\title{
The evolution of paste for backfill
}

\author{
D Stone Minefill Services, Inc., USA
}

\begin{abstract}
Paste thickened tailings backfills have undergone a rapid evolution from their first applications in the early 1990s, and with it the industry has seen significant advances in both the technology and the equipment that is needed for the production, transport and placement of paste. In the early years, the production of paste was largely based on 'rules of thumb' and industry experience with conventional thickening systems hence paste performance failures were common. Nowadays, the production of paste is based on a much improved understanding of the rheology of thickened tailings, and the behaviour of non-Newtonian slurries. This paper will walk through the advances in the science of paste thickening of tailings, and the associated improvements in the equipment used for thickening, mixing, pumping and transport of these materials.
\end{abstract}

\section{Introduction}

My first introduction to mine backfills was over 30 years ago as a Ph.D. student studying under Dr Robert Mitchell at Queen's University. Many of you will recognise Dr Mitchell as an early pioneer in the empirical design of stable backfill exposures. The so-called Mitchell equations are still in use today for both vertical fill exposures, and for undercut sills. During my tenure at Queen's, Bob constructed the first geotechnical centrifuge for physical modelling of backfill exposures and this led a much better understanding of the geomechanics of backfills.

Since that time, my 30+ year career has taken me to all corners of the globe, from Papua New Guinea, to the Arctic in Canada. Like those of you from my generation, I was witness to the introduction of paste thickened tailings for backfill, and to its widespread adoption by the mining industry. The industry acceptance of paste for backfilling is quite remarkable, and in my mind it is the single greatest advance in the technology of mine fills since the Mine Fill Symposia series started in 1973.

This paper is intended as somewhat of a history lesson in the evolution of paste backfills, primarily for underground metal mines. While the early history of paste fills is well documented in a number of previous papers and keynote addresses, this paper leans more towards the science of paste thickening for backfills. This will lead to a discussion on the evolution of the technologies used in paste plants today.

\section{Before there was paste}

The earliest beginnings of paste thickened tailings for backfilling can be traced to South Africa and Canada in the mid to late 1970s where hydraulic backfill was the backfill of choice. At that time hydraulic fills were the standard, and they had been widely used for over 50 years. With the large scale commercialisation of Portland cement in the 1960s, cemented hydraulic fills allowed bulk mining of large open stopes without the need to leave pillars.

Hydraulic fills were relatively cheap because of the availability of mill tailings, they were easy to classify and dewater by cycloning, and they were easy to transport to stopes in small diameter pipelines - typically without pumping. The downside with hydraulic fills, however, was they created huge volumes of dirty decant water for the mine to deal with, and they consumed vast quantities of cement when fill strengths needed to be over 200 or $300 \mathrm{kPa}$. As the stopes got larger, and cement costs escalated, binder costs could easily account for $60-70 \%$ of the cost of the fill.

In the early years of hydraulic fill, before the introduction of more modern grinding and flotation equipment, the particle size distribution of gold mill tailings was quite coarse. Grinds were typically less 
than $50 \%$ passing 74 microns and these materials were ideally suited to hydraulic fills. However, by the late 1970 s grinds were getting finer and problems arose with percolation rates in the fills which only aggravated the issues of cement consumption.

In South Africa the excess mine water was a major cost issue because the water had to be pumped back to the surface. This led to research on ways to produce hydraulic fills with less free water, but still render them pumpable. The result was the so-called 'dense fill' or 'high density backfill' that was essentially what we now refer to as thickened tailings. Compared to the 55-65 wt\% solids in hydraulic fills, these new fills reached pulp densities in the high 60 s and low 70 s wt $\%$ solids. This reduced the free water by almost $50 \%$.

The two stumbling blocks with these systems were: (i) how to dewater the tailings, and (ii) pumping thickened tailings was beyond the capabilities of most pumps in that day. Even with piston pumps the practical limit was thought to be about $1 \mathrm{~km}$ of pipe.

The dewatering issue was highlighted in a SAIMM paper which noted "the equipment at present available is either of unsuitable mechanical complexity and size or is relatively untried" (Patchet 1977). By the late 1970s several methods of thickening hydraulic fills were being investigated. Some of the more novel methods included vibrating the sands in the stope after placement, batching in settling tanks and then drawing from bottom of the tank, and centrifuging.

By 1976 the South Africans were experimenting with centrifuges for dewatering total tailings streams. At the leading edge of this work was the 'Tailspinner' (Wayment 1978) introduced by Joy Manufacturing of Cambridge, Ontario, around 1972. Operating at about 1,500-3,000 rpm, this device allowed for the continuous dewatering of a slurry stream from an inlet solids content of about $40-60 \%$ solids by weight, to an outlet solids content of $75-85 \%$ solids. The device was designed to dewater the entire tailings stream, and the discharge generally contained less than $1 \%$ solids. The device was compact and fit in an approximately $1.2 \mathrm{~m}$ cube which allowed it to be portable. The South Africans took this concept to a prototype stage and installed a Tailspinner underground in the Witwatersrand basin.

The Tailspinner could produce a material that was just short of filter cake, e.g. a high yield stress paste, which had to be pneumatically stowed. The biggest disadvantage with the Tailspinner, however, was the throughput was limited to about $15 \mathrm{t} / \mathrm{h}$. The other disadvantage was that all the dewatering was done underground at the stope in order to avoid having to pump thickened tailings.

By the early 1980s Tailspinners were in use in Canada at South Porcupine and the Dome Mine in Ontario, marking the first introduction of a form of paste fill in Canada. Like the Africans, the Canadians did not believe in pumping paste in the early to late 1980s.

\section{The science behind paste rheology}

The industry seems to have adopted a rule of thumb that paste must contain more than $15 \%$ passing 20 microns. The fines, it is said, make the paste slippery so that it can be pumped easier. Even the Australian Centre for Geomechanics 'Handbook on Mine Fill' shows a figure (Figure 6.4) illustrating this so-called 'plug flow' model (Henderson et al. 2005, p. 84). A paste that is deficient in fines ( $<325$ mesh) will typically exhibit much higher pipe friction losses during transport.

I have often wondered who came up with these ideas, and it is probably no coincidence that is also found in concrete technology. It seems that a lot of the early ideas and research into the pumping of pastes are rooted in concrete technology. Some of you may recall that in the very early days paste was not considered to be pumpable (Landriault 1992).

Consider the standard 1:2:3 recipe for concrete mixes which says you add one part cement to two parts sand and three parts gravel. This results in a concrete mix with roughly $15 \%$ cement (aka fines) by weight. It should not be a surprise that in concrete transport, the cement is also thought to be responsible for making the pipe walls slippery so that it can be pumped. 
It should also not be a surprise that the industry adopted the ASTM International standard concrete slump cone as a measure of the rheology of a paste mix. Even today most mines design their paste mixes based on a target slump.

One of the earliest researchers into the science of rheology of paste mixes was Neels Verkerk (Verkerk 1988). Thanks to his early work, we now recognise that the behaviour of Bingham plastic and non-Newtonian slurries is governed by viscosity and yield stress. Verkerk produced some of the earliest tailings rheograms along with research on pressure gradients at varying flow rates.

Nowadays we understand that the stability and pumpability of a paste mix is dependant on yield stress and viscosity. Up until the mid-1990s these terms were rarely heard in reference to backfills. However in the past 25 years the depth of understanding of the rheology of paste mixes has expanded considerably.

The reality is that the stability and pumpability of a paste mix is complex and is impacted by a number of variables such as the mineralogy of the solids, specific gravity of the solids, particle size distribution, particle shapes, clay content and clay mineralogy, salts or other dissolved chemicals in the carrier fluid, and even the $\mathrm{pH}$ or temperature. It is no wonder that early paste mixes were largely designed on trial and error, and even today these mixes are highly sensitive to changes in the ore mineralogy, oxide content, and changes in the mill grind.

\section{$4 \quad$ Making paste}

\subsection{Dewatering with hydrocyclones}

The cyclone has played a dominant role in both dewatering for hydraulic fills, but also for classifying the material to remove the slimes portion of the tailings.

The idea of using centrifugal forces to separate liquids and solids in a hydrocyclone was first patented in 1891. This first generation of cyclone had a closed apex that allowed intermittent discharge and was the forerunner to present day desanders that are used for separating sand from water in pressurised water systems.

The present day cyclones can be traced back to patents in the 1940s by the Dutch State Mining Company which developed designs for the removal of sand from coal. These patents were licensed to the Dorr Company, the predecessor to Dorr-Oliver, around 1948 who then commercialised the equipment. In 1955, Krebs Engineers started manufacturing their own version that eventually dominated the market. The basic design of the modern day cyclone has not really changed in the 60 years since then.

\subsection{Thickening}

We could, and others have, fill many keynote addresses talking about the evolution of thickeners, flocculants, and underflow characteristics. In my view the evolution of the thickener has contributed the most to adoption of paste for backfilling. A large number of paste backfill systems today are based solely on paste thickened underflows.

The beginnings of the modern thickener started in 1906 when John Dorr patented the first continuous thickener with a circular tank and a set of rakes. Since that beginning, the basic thickener design has seen significant advancements to increase throughput, and to push the operating limits in terms of solids concentrations and yield stresses. Some of the more significant improvements include flocculant chemistry, rake designs, feed wells and feed dilution, dewatering pickets, shear thinning, reinjection of underflow to improve bed movement, tank designs and tank geometries, and modern computerised instrumentation and control systems. Numerical modelling of the beds has resulted in significant performance improvements, and structural modelling of the tanks and rakes has allowed these facilities to reach today's enormous sizes of $90 \mathrm{~m}$ diameter and more. 
Nowadays we have a range of thickeners designed to meet different needs. Conventional thickeners for thickening tailings, for the production of tailings slurries, typically have underflows with $50-55 \%$ solids and 20-30 Pa yield stress. High rate thickeners generally have an increased bed height to increase self-consolidation and produce underflows in the 55-60\% solids range and $30-100$ Pa yield stress. Paste thickeners have much deeper beds, hence the reference to 'deep cone' and 'deep bed', and are designed to produce an underflow material in the paste range of yield stresses $(>100 \mathrm{~Pa})$. Both high rate and paste thickeners have the capability of producing underflow in the paste range of yield stresses.

The origins of modern paste thickening units date to the late 1970s and early 1980s when the alumina industry was looking for ways to dewater bauxite residues to improve water recycling and to allow the dry stacking of red muds. Both Alcoa and Alcan developed technologies that were the forerunners to today's paste thickener units. The first of these units was constructed by Alcoa at Pinjarra in Western Australia in 1985, and Alcan had other units underway in Jamaica and Quebec. In 1996 Alcan signed a technology sharing agreement with Eimco to bring this technology to non-alumina industries and the rest is history.

By all accounts there are some 300 or more paste thickeners installed worldwide, operating at close to 100 mine sites. Not all of these are for backfilling as many of them produce thickened tailings for surface disposal. However, there are even more high rate or high compression thickeners in use, and these are typically dedicated to surface disposal of thickened tailings.

\subsection{Filtration}

Like thickening, filtration has always played an important role in tailings dewatering. Dating back to the early 1900s, filtration has been used to dewater coal residues, remove cyanide laden water from gold tailings, and to dewater concentrates prior to shipping.

However, unlike thickening, which has been the subject of intense research and development, there are surprisingly few papers on filtration.

The reality appears to be that filtration equipment, for the most part, has not changed much in the last 100 years. Filter presses for mineral plants have been available since 1903 . Vacuum filtration also dates back more than 100 years.

What has changed in the past 100 years, and especially the last 10 years, is the capital and operating cost of filter presses and vacuum filter units. It does not seem that long ago when Larox first introduced its large tonnage vertical filter press units for tailings dewatering and these units ran into the millions of dollars. Nowadays you can buy a Chinese made horizontal filter press for a couple of hundred thousand dollars.

Filtration has long been used in backfill circuits both in conjunction with cycloning, and without. Boliden used vacuum filters to produce a filter cake at their Garpenberg mines in the 1980s. The filter cake was then reslurried to $74 \%$ solids with $18 \%$ cement to produce a high strength hydraulic fill for tight floors (Brackebusch 1988). This concept formed the basis for the flow sheet at the Lucky Friday Mine; albeit they produced paste at $82 \%$ solids. Bad Grund also mixed filter cake with aggregate to create their paste product. In fact almost every paste plant built to date makes some use of filtration for dewatering of tailings.

\section{$5 \quad$ Transporting paste}

As I have already noted, the rapid advancement of paste was largely due to our understanding of concrete rheology and transport at the time. This impacted the evolution of paste in two ways, one was the mix design, and the second was the design of the distribution system.

Inco was one of the first to investigate the connection between the rheology of concrete and the pumpability of high density tailings and paste mixes (Landriault \& Goard 1987). As Landriault notes, "any granular material could be pumped like concrete if it was mixed with a sufficient quantity of a suitably fine material". Inco's research focused on the variation in pressure losses over a range of fines contents, and 
not surprisingly, the lowest pipe pressures were noted in materials with $10-14 \%$ fines, and $14-19 \%$ water content - just like concrete (Landriault 1983).

About the same time, the South Africans were realising that it was far easier to distribute paste mixes by gravity than it was to push it with pumps. In an effort to reduce pipe friction, the South Africans tried adding crushed aggregate to the paste mixes. Flow loop testing showed that mixes with crushed rock exhibited lower pipe friction losses than paste mixes based on tailings alone. This seems kind of counter-intuitive, but again, drawing on the concrete experience, the coarse fraction was thought to create a plug flow in the pipeline whereas the fines were meant to lubricate the inside of the pipe. The Bad Grund Mine in Germany took advantage of this when they started up in 1988, as did many early paste systems in South Africa.

Verkerk (1988) discovered the conundrum in that, in laminar flow conditions, increasing the coarse fraction of whole tailings mixes results in increasing yield stresses and increasing pressure gradients. This behaviour was thought to be the result of the coarse fraction sinking to the bottom of the pipe and creating a sliding bed regime. However, in the non-Newtonian range the opposite is true and pressure losses go down as the coarse fraction is increased. Apart from the plug flow behaviour noted previously, another explanation was that the coarse fraction displaced water hence increasing the water content in the carrier media concentrated along the edges of the plug flow thus lowering the frictional resistance. It was shown that, in order to reduce pipe friction losses, the carrier media must have a measurable yield stress.

Early attempts to pump thickened whole tailings with positive displacement pumps did not end well. In most cases the pumps failed prematurely due to excessive wear on a number of parts, including poppet valves and valve seats, and blockages in internal passages (Patchet 1977). This led to an industry acceptance that paste could not be pumped. Landriault (1992) noted that Inco used gravity flow exclusively, and by 1994 Fred Brackebusch suggested that the maximum distance a paste can practically be pumped is about $1 \mathrm{~km}$ (Brackebusch 1994). By $1998 \mathrm{Fred} \mathrm{had} \mathrm{changed} \mathrm{his} \mathrm{mind} \mathrm{and} \mathrm{suggested} \mathrm{the} \mathrm{limit} \mathrm{was}$ now $3 \mathrm{~km}$. Thompson et al. (1972) provides an even earlier benchmark noting that the maximum capability of a double piston positive displacement pump was 1,750 hp (1.3 MW) operating at under 2,000 psi (13.8 MPa).

Even though the basic operating principle of these pumps has not changed much since the mid to late 1990s, pumps have undergone significant improvements in the range of operating pressures, available power, and wear-life of the components. Many positive displacement pumps are now capable of pressures of 15-20 MPa flow rates in excess of $200 \mathrm{~m}^{3} / \mathrm{h}$.

The final hurdle in getting these systems to work was the distribution piping itself. There were some hard lessons learned here, but again the concrete industry had been through the same learning curve. A number of operations such as Lucky Friday, and even Inco, learned that dropping paste vertically down an empty shaft pipe was a recipe for disaster. The momentum and forces involved were beyond the capability of pipe steel and mounting hardware in those days, and blowouts were common. It was quickly learned that it was much safer to operate paste systems with a full pipe but this required much more elaborate control systems and flushing mechanisms.

The next lesson was how to pump the material without plugging the pipe. In this instance it was quickly learned that rheology was the key and that most systems could be designed for an ideal yield stress (slump) that would prevent excessive pressures, reduce pipe wear, and prevent cavitation.

\section{Paste goes mainstream}

Once all the bugs were worked out it did not take paste long to become the backfill of choice. By late 1994 there were several plants in operation in Canada, and by the year 2000 there were some 22 plants in operation (Landriault 2000). My best guess is that over 150 paste plants have now been built but not all are operating. The Golder files contain some 50 paste plants that have been built, and since 2000 the industry has been adding about five new plants per year. 
In Canada and Australia, paste quickly replaced cemented rockfill as the backfill of choice because it could achieve the compressive strengths needed in large blasthole stoping operations. In other parts of the world, especially Peru, it replaced hydraulic fills. In Nevada it took until 2010 before regulators could be convinced that cyanide tailings could be used as paste for backfill in an operating mine and Barrick commissioned the first plant in 2012.

A brief timeline of the chronology of some of the major milestones in the evolution of paste is given in Table 1.

Table 1 Chronology of events in the evolution of paste

\begin{tabular}{ll}
\hline Year & \multicolumn{1}{c}{ Event } \\
\hline 1978 & First mention of 'paste' in a paper by Wayment (1978) \\
1984 & First paste plant built in Australia at Elura (Barrett, 2000) \\
1985 & First Alcoa super-thickener at Pinjarra in Western Australia \\
1988 & First paper on paste rheology by Verkerk (1988) \\
1988 & First paste plant in the US at Lucky Friday \\
1994 & First paste plant in Canada at Inco Garson \\
1996 & Alcan-Eimco technology sharing agreement \\
& First deep cone thickeners outside the alumina industry \\
1997 & Golder Pastec formed \\
1997 & First operational paste plant in Australia at Henty \\
1998 & First paste plant in Brazil at Cariaba \\
1998 & First plant built by Pastec at Cannington, Australia \\
2000 & 22 paste plants operating \\
2006 & Over 40 paste plants operating \\
2012 & First paste plant in Nevada at Barrick Goldstrike \\
\hline
\end{tabular}

${ }^{1}$ Note - this first attempt at an operational paste plant was reported to be failure and the plant was later converted to hydraulic fill.

The rapid adoption of paste is ideally illustrated in the proceedings for previous Mine Fill Symposia. Table 2 is a summary of paste backfill related papers in the proceedings since the Mine Fill Symposia series started in 1973. 
Table 2 Paste related papers presented in previous Mine Fill Symposia

\begin{tabular}{lc}
\hline \multicolumn{1}{c}{ Symposia } & Paste related papers \\
\hline 1973 - Mount Isa & 0 \\
1978 - Sudbury & 0 \\
1983 - Montreal & 0 \\
1989 - Sweden & 2 \\
1993 - South Africa & 2 \\
1998 - Brisbane & 12 \\
2001 - Seattle & 11 \\
2004 - Beijing & 11 \\
2007 - Montreal & 13 \\
2011 - Cape Town & 10 \\
2014 - Perth & 22 \\
\hline
\end{tabular}

The first Mine Fill Symposia papers to refer to 'paste' backfill were published in the 1989 proceedings. One of these papers addressed the liquefaction potential of paste for backfill at the Dome Mine in Canada which, at the time, was viewed as a key risk with implementation. The other paper by Dave Landriault compared the convergence resistance of a variety of backfill types including paste fills.

In 1999 the Australian Centre for Geomechanics premiered the first annual seminar for 'Paste and Thickened Tailings', and it has been a valuable forum for the sharing of this rapidly evolving science (Boger 2011). While this seminar series is targeted more towards surface disposal and technology, it does draw papers related to mine backfilling. In 2010 it attracted a record 12 papers related to paste for backfill, therein documenting what would appear to be a peak in the start-up of new paste plants.

\section{Conclusion}

It is hard to believe that paste backfills have been successful for more than $\mathbf{3 0}$ years, thanks to the many innovations in rheology and equipment. The benefits speak for themselves.

\section{Acknowledgement}

The author acknowledges the many contributions by previous keynote speakers in the Mine Fill Symposia, and the Australian Centre for Geomechanics Paste and Thickened Tailings seminars which were the source of much of my research. I also acknowledge the support of Golder Associates.

\section{References}

Barrett, J 2000, 'Paste fill development in Australia - Lessons and Surprises', Paste Technology 2000 Seminar, Australian Centre for Geomechanics, Perth, Australia.

Boger, DV 2011, 'A personal perspective on paste and thickened tailings - a decade on', in RJ Jewell \& AB Fourie (eds), Proceedings of the 14th International Seminar on Paste and Thickened Tailings, Australian Centre for Geomechanics, Perth, pp. 3-11.

Brackebusch, FW 1994, 'Basics of paste backfill systems', Mining Engineering, vol. 46, no. 10, pp. 1175-8.

Brackebusch, FW \& Shillabeer, J 1998, 'Use of paste for tailings disposal', in M Bloss (ed.), Proceedings of the Sixth International Symposium on Mining with Backfill, Australasian Institute of Mining and Metallurgy, Carlton, pp. 53-8.

Henderson, A, Revell, MB, Landriault, D \& Coxon, J 2005, 'Paste Fill', in Y Potvin, EG Thomas \& AB Fourie (eds), Handbook on Mine Fill, Australian Centre for Geomechanics, Perth, Western Australia.

Landriault, D 1983 'Preparation and placement of high density backfill', Underground Support Systems, CIMM Special Volume 35, pp. 95-104. 
Landriault, D \& Goard, B 1987, 'Research into high density backfill placement methods by the Ontario Division of Inco Limited' CIMM Bulletin, vol. 80, no. 897, pp. 46-50.

Landriault, D 1992 'Inco's backfill experience', Canadian Mining Journal, vol. 113, no. 2, pp. 39-46.

Landriault, D 2000, 'What is thickened tailings and what is paste', Proceedings of Paste Technology 2000 - An International Seminar on the Production and Disposal of Thickened/Paste Tailings for Mine Backfill or on the Surface, Australian Centre for Geomechanics, Perth, Section 3.

Patchet, SJ 1977, 'Fill support systems for deep level gold mines', Journal of the South African Institute of Mining and Metallurgy, September 1977, pp. 34-46.

Thompson, TL, Frey, RJ \& Wasp, EJ 1972, 'Slurry pumps - a survey', in HS Stephens \& WA Thornton (eds), Proceedings of the Second International Conference on Hydrotransport of Solids in Pipes, British Hydromechanics Research Association Fluid Engineering, Cranfield.

Verkerk, N 1988, 'Backfill slurries in South African gold mines', Journal of the South African Institute of Mining and Metallurgy, July 1988, pp. 390-400.

Wayment, WR 1978, 'Backfilling with tailings - a new approach', Proceedings of the 12th Canadian Rock Mechanics Symposia, Canadian Institute of Mining and Metallurgy, Montreal, pp. 111-6. 